\title{
Top Management Team Heterogeneity, Group Cohesion, Competitive Repertoire Complexity and Performance: Evidence from Kenyan Food and Beverage Manufacturers
}

\author{
Patriciah G. Mwangi \\ Doctoral Candidate \\ School of Business \\ University of Nairobi, Kenya \\ Zachary B. Awino \\ Associate Professor \\ School of Business \\ University of Nairobi, Kenya \\ Kennedy O. Ogollah \\ Lecturer \\ School of Business \\ University of Nairobi, Kenya \\ Ganesh P. Pokhariyal \\ Professor \\ School of Mathematics \\ University of Nairobi, Kenya
}

\begin{abstract}
This study sought to evaluate the relationship between top management team (TMT) heterogeneity, group cohesion, competitive repertoire complexity and firm performance. This study argued that top management team heterogeneity could affect performance positively or negatively due to the increased ability to deploy a wide range of strategies and increased divisions respectively. Group cohesion was also associated with positive and negative firm performance depending on the group context while competitive repertoire complexity was associated with mixed performance effects. A cross sectional descriptive survey was conducted among 53 large food and beverage manufacturing firms through primary and secondary data which was analyzed through multivariate regression analysis. The study established that TMT heterogeneity, group cohesion and competitive repertoire complexity jointly affected all performance measures except environmental performance. This implied that organizations needed to approach TMT heterogeneity and competitive repertoire complexity cautiously and undertake measures to foster cohesion in the TMT to enhance performance.
\end{abstract}

Keywords: Top management team heterogeneity, Group cohesion, Competitive repertoire complexity, Performance, Food and beverage manufacturing firms.

\section{Introduction}

The performance of the organization is important to the stakeholders regardless of the form of the organization. Richard, Devinney, Yip and Johnson (2009) noted that firm performance is essential in evaluating its actions and environments. It is through performance that stakeholders can judge whether the goals and plans of the organization are being met or not. The better the performance of the organization, the more likely it is that the stakeholders are satisfied. Due to this, organization stakeholders are always seeking what can be done to improve its performance. Awino (2013) observed that organizational performance was accounted for by multiple factors. This is because organizational performance is multifaceted and different factors affect performance differently. This study investigated the effect of top management team (TMT) heterogeneity, group cohesion and competitive repertoire complexity. Hambrick and Mason (1984) proposed that to understand the actions of an organization, one must consider the most important actors in the organization that is the top managers. 
This is because the top managers determine the strategic decisions and direction of the organization which influences performance. Pitcher and Smith (2001) noted that there are few more important subjects to strategy scholars and practitioners than the link between the people at the apex of the firm and its performance. In a bid to derive the most out of the TMT, organizations incorporate managers with a variety of skills (Ancona \& Caldwell, 1992) with the view that the TMT is able to launch superior strategies leading to organization success. This leads to TMT heterogeneity whereby the attributes of the senior managers are diverse.

TMT heterogeneity on the overall affects performance. Due to the variety of skills, talents and experiences vested in a heterogeneous TMT, the information processing ability of the TMT is elevated. Further, a heterogeneous TMT can launch a wide array of competitive moves that make it difficult for the competition to catch up. Keck (1997) and Wiersema and Bantel (1992) investigated and established that TMT heterogeneity affected firm performance significantly. Certo, Lester, Dalton and Dalton (2006) found significant relationship between the size of the TMT, functional heterogeneity and tenure heterogeneity and organization performance. However they cautioned that the relationships were ambiguous at best due to differences in TMT operationalization and existing moderating factors to this relationship.

Groups are common in human society and given their environments their formation takes different approaches (Banwo, Du \& Onokala, 2015). Lau and Murnighan (1998) noted that there were two growing trends in organizations which were the use of groups and the diversity in organizations. This indicates the growing need to understand the groups that make up the organization. The TMT in an organization is a group with the dynamics of any other group and thus to properly understand it, we must understand its dynamics. Greer (2012) observed that due to the universality of groups, scholars in various fields had tried to study group dynamics and its construct group cohesion.

Group cohesion implies the extent to which individuals feel part of the group, are committed to its goals and work together to achieve them. Banwo et al (2015) defined group cohesion as the complete influences, exogenous and endogenous, working on members to stay within the team. It reflects the inclination of the group to bond, stick together, and stay unified in pursuing group goals and organizational objectives. A cohesive group is able to pull in the same direction. Beal, Cohen, Burke and McLendon (2003) posited that when cohesion is strong a group is encouraged to perform well and can coordinate its activities to succeed. Chang, Duck and Bordia (2006) noted that group cohesion was a multidimensional construct that focuses on the group's integration and the individual's appeal to the group. Due to this, group cohesion may have different effects on performance.

The TMT affects performance through their choice of strategies and a heterogeneous TMT is associated with competitive repertoire complexity. Competitive repertoire complexity refers to a situation where a wide range of competitive moves is engaged and consists of different types of moves. In this case the range of moves is wide and the actions are not concentrated to any type of actions. Connelly, Tihanyi, Ketchen, Carnes and Ferrier (2017) noted that as competition progresses, organizations find it necessary to engage opponents with a complicated array of moves. This allows the firm to counter an evolving environment in a better manner and gain competitive advantage. Ferrier and Lyon (2004) noted that firms differ in their repertoire complexity driven by their managers' lens of experience which affects performance differently in the short and long run.

Competitive repertoire complexity is connected to performance especially in the long run. This is because consistent with the resource based view, complex actions make it difficult for rivals to mimic. Offstein (2004) observed that firms' competitive behaviour is important theoretically and empirically since it is linked to financial performance. He argued that competitive repertoire complexity allowed a firm to spread its bases of competitive advantage and maintain them over time. This is because rivals are unable to predict the firm's actions and respond to them. Ndofor, Sirmon and He (2011) established that complexity allowed the firm to use its resources effectively leading to better performance. In addition, competitive repertoire complexity affords a heterogeneous TMT with opportunity to exercise their collective abilities which affects performance.

\section{Literature Review}

This study was anchored by the upper echelons theory which holds that managers' characteristics determine their choices of strategy and firm outcomes (Hambrick \& Mason, 1984). Therefore, TMT heterogeneity influences organization performance. It was also supported by the resource based view, the self categorization theory and the information processing theory. 
The resource based view posits that organizations with valuable, unusual and unmatched resources outperform their competitors (Oh \& Kuchinke, 2017; Barney, 2001) whereby TMT heterogeneity, group cohesion and competitive actions are resources that can be deployed for competitive advantage. The self categorization theory posits that individuals categorize themselves as part of the group or not which determines group cohesiveness (Hogg \& Terry, 2000). The information processing theory holds that people gather information, process it and store it for decision making (Hult, Ketchen \& Slater, 2004). A heterogeneous TMT is more likely to launch and support competitive repertoire complexity due to its broader perspectives and experiences.

Various scholars have concluded TMT heterogeneity affects performance however this relationship is not wholly direct. Certo et al. (2006) in their meta-analysis concluded that the evidence for a direct relationship between TMT heterogeneity and firm performance was largely equivocal. Knight et al. (1999) in their study established that TMT heterogeneity did not significantly influence strategic consensus unless group variables were factored in since TMT heterogeneity can either trigger the benefits of the group or the dysfunctions. TMT heterogeneity can therefore be beneficial or harmful to performance which could explain the mixed results in previous studies. If the TMT members are divided by their differences, then performance is affected negatively. However, if the TMT members are able to harness their differences and work together, there is positive effect on performance. Thus TMT heterogeneity may result in group fragmentation or group cohesiveness.

Group cohesiveness does not always result in positive performance. This is because it depends on the context the group is working in. A group can deploy its togetherness to fight organizational objectives or to support them. Banwo et al. (2015) in their study established that group cohesion could influence performance in a positive or negative direction contingent on the context. This implies the need to focus on context of the group. Shin and Park (2009) established that cohesion had a negative moderating effect at individual levels but a positive one at group level in competency-performance relationships implying the need to review the group context. This implies that group cohesion can lead to otherwise high performing members reducing their efforts to conform to the group. However, on a group level cohesion had a positive effect meaning that on group tasks a cohesive group performs better. The work context of the group therefore is important in determining the effect that cohesion has on the performance of the group.

Carpenter (2002) provided the background against which a TMT works in. In his study he proposed two contexts that need to be considered in TMT studies that is the social context and the strategy context. This implies that the social interactions of the TMT and organizational strategies affect the TMT. Deszo and Ross (2012) in their study established that female representation in the TMT improved performance as long as the firm focused on innovation strategy. This is because the strategy provides a context for the informational and collective advantages of the gender variety and the conduct of women in management needed for performance. This supports the findings by Carpenter (2002) in that the strategy provides a background in which the benefits of TMT heterogeneity can be felt.

On the other hand, competitive repertoire complexity also affects the cohesiveness of the group. Carpenter (2002) demonstrated that TMT heterogeneity had a positive impact on firm performance at lower stages of complexity but a negative one at higher levels due to accelerated conflict. Lubatkin, Simsek, Ling and Veiga (2006) studying small and medium firms in New England noted that the firm's ambidexterity is largely dependent on the TMTs internal dynamics that endowed the TMT with capacity to process huge quantities of information and decision options and handle conflict and uncertainty. Competitive repertoire complexity increases the pressure on the TMT to process wide loads of information and can therefore trigger disagreements among the TMT especially when it is not cohesive. Thus TMT heterogeneity, group cohesion and competitive repertoire complexity potentially affect corporate performance jointly. This study therefore proposed that:

\section{TMT heterogeneity, group cohesion and competitive repertoire complexity have no significant joint effect on firm performance}

\section{Methodology}

This study was conducted among 53 large food and beverage manufacturing firms by applying a cross sectional descriptive survey. Primary data was obtained through a structured questionnaire while secondary data relating to financial performance was obtained from the Kenya Revenue Authority for the five year period between 2012 and 2016. The data was then analyzed using multivariate regression analysis. 
TMT heterogeneity was measured as a composite of age, gender, education level, functional background and tenure heterogeneities, group cohesion was measured in terms of task and social cohesion while competitive repertoire complexity was measured in terms of competitive repertoire range.

\section{Results}

This study proposed that TMT heterogeneity, group cohesion and competitive repertoire complexity have no significant joint effect on firm performance. This hypothesis was tested against financial, customer, internal processes, learning and development, social and environmental performance. The results shown in Table 4.1 indicated that TMT heterogeneity, group cohesion and competitive repertoire complexity had a significant joint effect on all performance measures of performance except environmental performance as evidenced by $p$ values less than 0.05 .

Table 4.2 further revealed that on the overall TMT heterogeneity had a negative effect on all performance perspectives. Group cohesion had a positive effect on all performance measures. Finally competitive repertoire complexity had a positive effect on financial performance and a negative effect on all the non financial measures of performance.

\section{Discussions and Conclusions}

The study established that TMT heterogeneity, group cohesion and competitive repertoire complexity jointly affected all performance perspectives significantly except for environmental performance. This confirmed the findings by Certo et al (2006) that the relationship between TMT heterogeneity and firm performance was not a direct one. Further, Knight et al (1999) established that TMT heterogeneity did not significantly affect strategic consensus if group processes were not considered. This study therefore rejected the hypothesis that TMT heterogeneity, group cohesion and competitive repertoire complexity have no significant joint effect on firm performance as far as all the performance measures were concerned except for environmental performance.

This study also established that when the variables were considered together, TMT heterogeneity had a negative effect on all the performance perspectives while group cohesion had a positive effect on all performance perspectives and competitive repertoire complexity had a negative effect on all performance measures except financial performance. This implied that TMT heterogeneity and competitive repertoire complexity tended to be harmful to performance unless the TMT was cohesive. This supported the findings by Carpenter (2002) that TMT heterogeneity had a negative effect on performance for firms with high complexity due to increased conflict among the TMT. Unless the TMT was able to work together, differences in the TMT characteristics and deployment of a large number of various competitive actions would impair firm performance. This was also consistent with Connelly et al (2017) who found that competitive repertoire complexity was harmful to performance in the short term and could overburden the TMT in the long term.

\section{Implications of the Study}

This study was anchored on the upper echelons theory and the variables were also supported by the self categorization theory and the resource based view. The study established that on the overall TMT heterogeneity had a significant effect on business performance consistent with the upper echelons theory. It also demonstrated that a cohesive TMT had a positive effect on firm performance thereby providing empirical evidence to support the assertions of the self categorization theory. Finally, it revealed that TMT heterogeneity, group cohesion and competitive repertoire can be sources of competitive benefit for a firm when properly deployed as envisioned by the resource based view.

This study determined that TMT heterogeneity had the potential to harm firm performance. This would inform policy makers to be cautious in trying to introduce diversity in management teams. This implied that organizations would need to draft policies for recruitment, selection, training and development that would ensure more balance in the TMT. Further, organizations would benefit by addressing cohesion among their TMTs. Policy makers and managers would benefit in adopting measures such as team building activities, team meetings, team objectives, openness to suggestions and support and communication channels to foster cohesion in their attempts to diversify their management teams. The study demonstrated that the competitive repertoire complexity had a significant effect on performance. Specifically, it affected financial performance positively but was harmful to the other performance perspectives. This would be informative to strategists in the food and beverage manufacturing sector in developing competitive actions. 
A wide scope of competitive moves of different types would yield financial benefits but at the expense of other performance perspectives. The study noted that competitive actions in the sector were riddled with incidental activities which had not been strategically initiated by the TMT. Strategists in these firms would therefore benefit from a clear review of their strategic planning process to balance the positive effect on financial performance and the negative effect on other organization performance measures.

\section{References}

Ancona, D.G. \& Caldwell, D.F. (1992). Demography and Design: Predictions of New Product Team Performance. Organization Science. 3(3), 321-341.

Awino, Z.B. (2013). Top Management Team Diversity, Quality Decisions and Organizational Performance in the Service Industry. Journal of Management and Strategy. 4(1), 113-123.

Banwo, A.O., Du, J. \& Onokala, U. (2015). The Impact of Group Cohesiveness on Organizational Performance: The Nigerian Case. International Journal of Business and Management. 10(6), 146-154.

Barney, J.B. (2001). Resource-based Theories of Competitive Advantage: A Ten Year Retrospective on the Resource-based View. Journal of Management. 27(6), 643-650

Beal, D.J., Cohen, R.R., Burke, M.J. \& McLendon, C.L. (2003). Cohesion and Performance in Groups: A MetaAnalytic Clarification of Construct Relations. Journal of Applied Psychology. 88(6), 989-1004.

Carpenter, M.A. (2002). The implications of strategy and social context for the relationship between top management team heterogeneity and firm performance. Strategic Management Journal, 23(3), 275-284.

Certo, S.T., Lester, R.H., Dalton, C.M. \& Dalton, D.R. (2006). Top Management Teams, Strategy and Financial Performance. A Meta-Analytic Examination. Journal of Management Studies. 43(4), 813-839.

Chang, A., Duck, J. \& Bordia, P. (2006). Understanding the Multidimensionality of Group Development. Small Group Research. 37(4), 327-350.

Connelly, B.L., Tihanyi, L., Ketchen, D.J., Carnes, C.M. \& Ferrier, W.J. (2017). Competitive repertoire complexity: Governance antecedents and performance outcomes. Strategic Management Journal, 38(5), 1151-1173.

Dezso, C.L. \& Ross, D.G. (2012). Does Female Representation in Top Management Improve Firm Performance? A Panel Data Investigation. Strategic Management Journal. 33(9), 1072-1089.

Ferrier, W.J. \& Lyon, D.W. (2004). Competitive Repertoire Simplicity and Firm Performance: The Moderating Role of Top Management Heterogeneity. Managerial and Decision Economics. 25(6-7), 317-327.

Greer, L.L. (2012). Group Cohesion: Then and Now. Small Group Research. 43(6), 655-661.

Hambrick, D.C. \& Mason, P.A. (1984). Upper Echelons: The Organization as a Reflection of Its Top Managers. Academy of Management Review. 9(2), 193-206.

Hogg, M.A. \& Terry, D.J. (2000). Social Identity and Self Categorization Processes in Organizational Contexts. Academy of Management Review. 25(1), 121-140.

Hult, G.T.M, Ketchen, D.V. \& Slater, S.F. (2004). Information Processing, Knowledge Development and Strategic Supply Chain Performance. Academy of Management Journal. 47(2), 241-253.

Keck, S.L. (1997). Top Management Team Structure: Differential Effects by Environmental Context. Organization Science. 8(2), 143-156.

Knight, D., Pearce, C.L., Smith, K.G., Olian, J.D., Sims, H.P., Smith, K. A. \& Flood, P. (1999). Top Management Team Diversity, Group Process and Strategic Consensus. Strategic Management Journal. 20(5), 445465.

Lau, D.C \& Murnighan, J.K. (1998). Demographic Diversity and Faultlines: The Compositional Dynamics of Organizational Groups. Academy of Management Review. 23(2), 325-340.

Lubatkin, M.H., Simsek, Z., Ling, Y. \& Veiga, J.F. (2006). Ambidexterity and Performance in Small to Medium Sized Firms: The Pivotal Role of Top Management Team Behavioral Integration. Journal of Management. 32(5), 646-672.

Ndofor, H.A., Sirmon, D.G. \& He, X. (2011). Firm Resources, Competitive Actions and Performance: Investigating a Mediated Model with Evidence from the In-Vitro Diagnostics Industry. Strategic Management Journal. 32(6), 640-657. 
Offstein, E.H. (2004). The Upper-Echelon Perspective of Firm Competitive Behavior: Empirical Evidence from the U.S. Pharmaceutical Industry (Unpublished Doctoral Thesis). Virginia Polytechnic Institute and State University

Oh, S.Y., \& Kuchinke, K.P. (2017). Exploring the role of organizational learning activities in the quality management context. Leadership \& Organization Development Journal, 38(3), 380-397.

Pitcher, P. \& Smith, A.D. (2001). Top Management Team Heterogeneity: Personality, Power and Proxies. Organization Science. 12(1), 1-18.

Richard, P.J., Devinney, T.M., Yip, G.S. \& Johnson, G. (2009). Measuring Organizational Performance: Towards Methodological Best Practice. Journal of Management. 35(3), 718-804.

Shin, S-Y. \& Park, W-W. (2009). Moderating Effects of Group Cohesiveness in Competency-Performance Relationships: A Multi-level Study. Journal of Behavioral Studies in Business. 1(1), 1- 15.

Wiersema, M.F. \& Bantel, K.A. (1992). Top Management Team Demography and Corporate Strategic Change. Academy of Management Journal. 35(1), 91-121.

\section{Appendices}

Table 4.1: Effect of TMT Heterogeneity \& Group Cohesion \& Repertoire Complexity on Performance

\begin{tabular}{|c|c|c|c|c|c|}
\hline Performance & $\mathbf{R}$ & $\begin{array}{l}\mathbf{R} \\
\text { square }\end{array}$ & $\mathbf{F}$ & Sig. & Conclusion \\
\hline Financial & 0.485 & 0.235 & 5.026 & 0.004 & Significant \\
\hline Customer & 0.429 & 0.184 & 3.681 & 0.018 & Significant \\
\hline Internal Processes & 0.537 & 0.288 & 6.353 & 0.001 & Significant \\
\hline Learning \& Development & 0.412 & 0.17 & 3.345 & 0.026 & Significant \\
\hline Social & 0.422 & 0.178 & 3.532 & 0.021 & Significant \\
\hline Environmental & 0.261 & 0.068 & 1.194 & 0.322 & Not Significant \\
\hline
\end{tabular}

Table 4.2: Unstandardized Coefficients for the Individual Variables on Performance

\begin{tabular}{llll}
\hline Performance & TMT Heterogeneity & $\begin{array}{l}\text { Group } \\
\text { Cohesion }\end{array}$ & $\begin{array}{l}\text { Competitive } \\
\text { Repertoire } \\
\text { Complexity }\end{array}$ \\
\hline Financial & -1.099 & 0.208 & 0.144 \\
Customer & -0.513 & 0.37 & -0.196 \\
Internal Processes & -2.107 & 0.333 & -0.227 \\
Learning \& Development & -0.472 & 0.291 & -0.153 \\
Social & -3.352 & 0.298 & -0.175 \\
Environmental & -1.996 & 0.183 & -0.093 \\
\hline
\end{tabular}

